\title{
NOTICIAS, OBSERVACIONES Y ALGO MÁS QUE OTRO PAÍS DE JUAN DE SOLÍS
}

\author{
POR \\ JOSÉ MANUEL CRUZ VALDOVINOS \\ Universidad Complutense de Madrid
}

\begin{abstract}
The following article handels about the painter Juan de Solís, who has been active in the spanish Court during the second quart of the 17 th century. We are told about different matters like his naming "pintor de las Caballerizas» of the Queen in 1640 and his death in 1654 and other ones already published are being specified. We also become to know about new signed works that will surely extend your litte catalogue.
\end{abstract}

En 1983 los profesores Angulo y Pérez Sánchez estudiaron por primera vez la figura del pintor Juan de Solís, activo en la corte madrileña en el segundo cuarto del siglo xvi añadiendo una serie de cuatro pinturas a la única publicada hasta entonces, que era la conservada en el museo de Navarra en Pamplona ${ }^{1}$. El segundo autor citado, en su manual de pintura barroca aparecido en 1992 dedica tan sólo unas líneas de síntesis al pintor, del que nada nuevo se había publicado en el decenio transcurrido desde el libro anterior, matizando la fecha de nacimiento, que coloca ahora hacia 1595 cuando antes sólo indicaba que hubo de tener lugar en los últimos años del siglo XVI ${ }^{2}$.

Pretendemos aportar en este trabajo unos pocos datos desconocidos hasta ahora, comentar algunas noticias desde variadas perspectivas y añadir un lienzo -o, quizá, varios más- a su corto catálogo.

Nada podemos precisar respecto a la fecha de su nacimiento que, evidentemente, hubo de suceder a fines del siglo xvI, ni sobre el aprendizaje que Ceán dice se realizó con el segoviano Alonso de Herrera. Su primer matrimonio con Isabel (según la inscripción del bautismo de su hija Francisca) o María (como se lee en el testamento de su hijo Francisco) del Castillo debió celebrarse en 1619 o antes. El 15 de marzo de 1620 fue bautizada la aludida Francisca en la parroquia de San Ginés. Aurora Miró ${ }^{3}$ ha sospechado que en realidad se trate de Francisco $(+1684)$, de quien no se ha encontrado la partida de bautismo en dicha parroquia; el testamento de Juan sólo menciona como hijos a Francisco y María. A nuestro parecer, es más fácil que la

\footnotetext{
1 Diego Angulo Iñíguez y Alfonso E. Pérez Sánchez, Pintura madrileña del segundo tercio del siglo XVII, Madrid, 1983 (CSIC, Instituto Diego Velázquez), 329-334, láms. 338-342.

2 Alfonso E. Pérez Sánchez, Pintura barroca en España. 1600-1750, Madrid, 1992 (Cátedra), 254.

3 Aurora Miro, «Francisco Solís», A.E.A. 184 (1973), 401.
} 
partida sea correcta y se trate de una hermana mayor de Francisco que muriera antes del nacimiento de éste y cuyo nombre se diera al nuevo hijo. Por tanto, sigue siendo un enigma la fecha en que nació el que luego llegaría a famoso pintor. Puesto que la primera obra datada que se conoce es de 1656 podría ser más adecuado el año 1629, como se deduce de Palomino, año en que, además, Juan era parroquiano de San Sebastián, aunque no cabe descartar completamente la de 1620 que admite Pérez Sánchez.

Según el mismo Palomino, Francisco fue hijo de padres nobles y Aurora Miró, en su estudio sobre este pintor, entrecomilla que Juan fue "recibido en esta villa en el estado de hijosdalgo", aunque no cita el documento de donde extrae este texto. Por nuestra parte podemos añadir que, además de confirmar lo dicho por Palomino, la noticia indica probablemente que Juan había litigado para obtener el reconocimiento de su hidalguía, presentando la ejecutoria ante el Concejo madrileño una vez conseguida; y, aún más, cabría aventurar que no había nacido en la villa, pues si sus progenitores hubieran vivido en Madrid se habrían hecho recibir en el estado de hijosdalgos, por lo que Juan de Solís no se hubiera visto precisado a hacerlo.

La noticia siguiente en orden cronológico, si bien publicada hace años, ha pasado inadvertida por lo que la recogemos aquí ${ }^{4}$. En la relación del donativo que se exigió por Felipe IV en 1625 para la defensa de los Reinos figura entre 73 pintores, viviendo en la calle de Hortaleza, con la cantidad de 12 reales que es una de las inferiores ${ }^{5}$. Es sorprendente que en la partida se haga constar «loco», pues ninguna noticia se conoce al respecto; si es verdad que llegó a estarlo, aunque dudamos de ello, es patente que sanó de su enfermedad.

El 18 de abril de 1629 tasó las pinturas dejadas por un desconocido Antonio Sánchez a su muerte, nombrado por su viuda Catalina Hernández del Castillo y sus hijos ${ }^{6}$. Vivía entonces «enfrente de la Vitoria, en cassas del ospital de la Corte». El hospital poseía varias casas pequeñas en el inicio de la carrera de San Jerónimo (lado izquierdo desde la Puerta del Sol) que, en efecto, quedaban enfrente del convento de San Francisco de Paula. Sería entonces parroquiano de San Sebastián y no de San Ginés como en 1620.

Hacia 1630 recibió como oficial al que sería famoso pintor de flores, Juan de Arellano, que había cumplido su aprendizaje con un pintor de Alcalá y tenía 16 años, según Palomino. Por esto se supone que su ingreso en el obrador de Solís no debe fecharse mucho más allá de ese año; se ignora hasta cuándo permaneció allí, pero luego nos referiremos a esta cuestión.

Según su testamento, Juan de Solís, tras enviudar, casó por segunda vez en 1632 con Mariana de Corcuera, de la que tuvo varios hijos pero a la muerte del pintor sólo vivía una niña de siete meses.

Angulo y Pérez Sánchez supusieron que hacia 1636 fue nombrado pintor de la Reina, pues Francisco de Solís, a la muerte de su padre en 1654, afirma que lo había sido unos dieciocho años. En nuestra opinión no existía aún nombramiento de tal, sino que, en torno a aquella fecha, Juan de Solís empezó a trabajar para el Buen Retiro y consiguientemente, para los Reyes. Así, María Luisa Caturla señala el comienzo de su labor en los decorados de comedias para el nuevo palacio entre los años 1635 y 1636, junto a Juan Bautista Sánchez y al napolitano Juan Bautista Santolus (+1648).

El 20 de abril de 1637 cobró por cuatro países para la ermita de San Pablo del Buen Retiro

\footnotetext{
4 María del Carmen González Muñoz, "Datos para un estudio de Madrid en la primera mitad del siglo xviI", A.I.E.M. XVIII (1981), 177. La noticia procede del libro 86 del inventario n ${ }^{\circ} 10$ de Contadurías generales del Archivo General de Simancas.

5 Carducho y Caxés ofrecieron 50.000 maravedís (algo más de 1470 reales) y Velázquez 1110 reales, Cornelis de Beer 300 reales, Andrea Ricci y Antonio de Salazar 200 reales y los demás 100 reales o menos.

6 A.H.P.M., escr. Bernardo de Santiago, prot. 3477, 59v-60v. Las diez pinturas, todas de asunto religioso, se valoraron en 1216 reales sin mencionar autor alguno.
} 
y una figura de Baco, un pedestal de retablo y otras pinturas para la ermita de la Magdalena, también en los jardines del palacio. Según Azcárate recibió por las obras la cantidad de 1038 reales y según Brown fueron $1034^{7}$. Este autor aprovecha para comentar el hecho como muestra de la escasa valoración que recibían algunos pintores "menores» cuyo trabajo se consideraba propio de «artesanos». Al margen de lo anacrónico e inexacto de los términos empleados, habría que destacar que en la jerarquía de los géneros pictóricos vigente en la época en toda Europa, los paisajes ocupaban un lugar entre los últimos peldaños y nada tiene de extraño un precio entre 200 y 250 reales por cada uno -si eran pequeños y con pocas figuras- como sucedió en esta ocasión.

Nadie, que sepamos, ha tratado de identificar los cuatro paisajes. En el inventario de 1701, tras la muerte de Carlos II, no figura ninguna obra a nombre de Juan de Solís, por lo que deducimos que no estaban firmados, pues sería extraño su traslado o desaparición. Encontramos tan sólo una serie de cuatro paisajes de no gran tamaño y baja valoración (240 reales cada uno salvo el inventariado en tercer lugar en 300) que podrían ser los que pintó Juan de Solis; en su descripción consta que uno tenía un caminante y un perro, otro unos ladrones despojando a un hombre, el tercero otros robando a otro y el cuarto unos soldados salteadores de caminos; sus medidas eran $165 \times 56$ $\mathrm{cm}$, en formato vertical, por otra parte no conocido en Solís ${ }^{8}$. Poco después se inventarían otros dos países del mismo tamaño (tasados en 240 y 360 reales), de un hombre con una escopeta y otro huyendo, y de dos hombres hablando, uno de ellos con escopeta; aunque no se dice que sean de la misma mano que los cuatro anteriores, probablemente lo serían, lo que hace menos probable la identificación propuesta con las obras de Solís ${ }^{9}$. Por su colocación en el inventario, es casi seguro que todas estas pinturas se hallaban en una ermita. Angulo y Pérez Sánchez piensan que serían paisajes con ermitaños por colgarse en la ermita de San Pablo, y aunque la propuesta no carece de lógica, diversos ejemplos ${ }^{10}$ demuestran que no necesariamente sus asuntos debían ser piadosos.

Tampoco se ha identificado el Baco, pues algunos cuadros representándole que aparecen en el citado inventario lo hacen formando parte de series de meses, lo que es obstáculo importante aunque no definitivo para su identificación con el de Solís. Lo que parece claro, como indicaron Angulo y Pérez Sánchez frente a la hipótesis formulada por Azcárate, es que no se trataba de la Magdalena (llamada Baco por confusión del amanuense). Al margen de que hubiera resultado de mayor precio, el retablo de la ermita de la Magdalena estaba compuesto por la estatua de la titular y un cuadro de La Magdalena ante el sepulcro en el cuerpo superior. Como a Solís se le pagó por el pedestal del retablo no hay que descartar que fuera autor de sus pinturas bajo las columnas -Magdalena despojándose y Magdalena en el desierto $(42 \times 21 \mathrm{~cm})-$ si no es que se ocupó de la pintura decorativa de la arquitectura ${ }^{11}$.

Entre septiembre de 1637 y agosto de 1639 cobró con Juan Bautista Santolus 4.100 reales por «las pinturas de barcos y teatros viejos que hicieron para la fiesta del estanque» en el Buen Retiro, seguramente la de la noche de San Juan de 1637. De estos trabajos con Santolus surgiría una relación que tuvo como consecuencia que su hijo Lucas entrara, tras morir el napolitano en 1648, como aprendiz en el obrador de Juan de Arellano, quien había abandonado el de Juan de Solís, donde Santolus le conocería.

7 José María de Azcárate, "Anales de la construcción del Buen Retiro", A.I.E.M. I (1966), 119; Johathan Brown y John H. Elliot, Un palacio para el Rey, Madrid, 1981 (Alianza), 96 y 285, nota 28. El documento en A.G.S., Tribunal Mayor de Cuentas, leg. 3764, fol. 56.

8 Inventarios reales. Testamentaría del rey Carlos II (ed. de Gloria Fernández Bayton), Madrid, 1981 (Museo del Prado), II, 344, n. ${ }^{\circ} 852$ a 855.

9 Ibidem, n. ${ }^{\circ} 860$ y 861

10 Para el palacio del Buen Retiro, por lo que respecta a pintores castellanos, se encargaron o compraron paisajes a Francisco Collantes, Matías Ximeno y Manuel de Acevedo, junto a Juan de Solís. Un poco más tarde, si no fue al mismo tiempo, llegarían los del Mallorquín.

11 Para las pinturas de la ermita de la Magdalena del Buen Retiro véase ibidem, 345-346, n. ${ }^{\circ}$ 866-868. 
Un hecho a primera vista sorprendente es que Juan de Solís no figure entre los pintores incluídos en el auto de 26 de junio de 1638 dictado por el contador Gabriel Pérez de Carrión que fijaba las cantidades que habían de cobrarse a 23 pintores madrileños por la alcabala de las pinturas vendidas en casas y tiendas en 1636 y 1637 12. Una explicación puede hallarse en que Solís trabajara en exclusiva para el Buen Retiro o en otros encargos palatinos en esos dos años, siendo exentas las obras para el Rey. Otra es que se trate de una lista incompleta y relativa tan sólo a los pintores que interpusieron recurso contra algún auto previo del contador, por lo que no figurarían quienes no lo recurrieron.

El 31 de marzo de 1639 fue nombrado albacea y testamentario por Isabel de Sedeño, esposa en segundas nupcias del batidor de oro Diego de Lario o Alario, junto a su marido designado heredero universal ${ }^{13}$. Isabel era hermana del pintor Jerónimo de Cabrera ${ }^{14}$ pero pensamos que la relación de Solís con ella provendría mejor de la vecindad, pues vivía también en la calle de Hortaleza, y de una relacin profesional con Diego Alario, a quien diez años más tarde el pintor nombraría a su vez testamentario.

No debía sobrarle trabajo a Solís y en 1639 probó otro camino para lograr obras. El 15 de marzo fue inscrito en el libro de Oficiales del arzobispado de Toledo, requisito necesario para que se le encargaran trabajos en las iglesias y ermitas del amplísimo territorio de su jurisdicción. Pero, en contra de lo que interpretaron Angulo y Pérez Sánchez, no consta que llegara a realizar obra alguna en aquella circunscripción. El libro de Obras, que contiene las encargadas de 1612 a 1644 , no recoge ninguna a nombre de Solís y no hay noticia posterior ${ }^{15}$. Tampoco el tipo de pintura conocida que Solís hizo a lo largo de su vida lleva a pensar que fuera especialmente apto para realizar lienzos para retablos y cuadros de altar, en que consistían las obras del arzobispado.

Es posible que el nombramiento de pintor real le hiciera reconsiderar sus intenciones de trabajar para Toledo. Solís sucedió en 1640 a Tomás de Maturana, fallecido, como pintor de las caballerizas de la Reina sin gajes, lo que no impidió que, según la costumbre, hubiera de pagar 3.750 maravedís de media anata por lo honorífico ${ }^{16}$. Ignoramos si Juan de Solís llegó a realizar las obras propias de su título, como sería seguramente el ornato de los coches reales, de manera similar, al menos en fondos de arboleda y boscaje, a lo que haría en decoraciones teatrales y festivas. El pintor conservó el título hasta su muerte y seguramente, aunque no se ha documentado por ahora, lo recibió entonces su hijo Francisco, que se titula pintor de la Reina, forma usada también por su padre y que a veces ha originado confusiones. Existían pintores del Rey y pintores de las caballerizas del Rey y de la Reina, nombrados abreviadamente pintor del Rey y de la Reina ${ }^{17}$.

12 La relación de los pintores fue publicada en Julián Gállego, El pintor de artesano a artista, Granada, 1976 (Universidad de Granada), 256-257.

13 A. H. P. M., escr. Cristóbal de Herrera, prot. 4864, 39-42. Entre los testigos figura un Juan Rodríguez, pintor.

14 Sobre Jernimo de Cabrera (1580/81-1618) que trabajó para el duque de Lerma en Valladolid y para Felipe II en El Escorial y El Pardo, donde se conservan sus únicas pinturas conocidas, véase Diego Angulo Iñiguez y Alfonso E. Pérez Sánchez, Historia de la pintura española. Escuela madrileña del primer tercio del siglo xVII, Madrid, 1969 (CSIC), 79-85, y Trinidad de Antonio, Jerónimo de Cabrera, un pintor del siglo XVII, "BSAA» LII (1986), 452-455. En el documento al que nos referimos se hace mención de una hija de Cabrera llamada María, desconocida hasta ahora, y de un hijo de ésta: Juan de Cabrera Acuña.

15 Los libros citados se conservan en el Archivo diocesano de Toledo. La inscripción de Juan de Solís figura en el fol. 306 del libro de Oficiales. Véase Manuel Gutiérrez García-Brazales, Artistas y artífices barrocos en el arzobispado de Toledo, Toledo, 1982, (Caja de Ahorros Provincial de Toledo), ad indicem.

16 A.G.P., Expedientes personales, caja 1294/36. Ya lo dio a conocer doña Pilar García Sepúlveda en su tesis de licenciatura que hizo bajo nuestra dirección.

17 Deseamos destacar la coincidencia nunca observada de que el 7 de marzo del mismo año 1640 Mateo Núñez de Sepúlveda, que residía en Sevilla, fue nombrado pintor, dorador y maestro mayor de la pintura de las armadas del mar Océano, galeras de España, galeones de la plata que iban a Tierra Firme, escuadras reales de factorías y demás bajeles. Cfr. Juan Antonio Ceán Bermúdez, Diccionario..., Madrid 1800, III, 241-242. Solís fue nombrado pintor de las caballerizas y Núñez pintor de las armadas. Indiquemos, de pasada, que en 1640 era pintor de las caballerizas del Rey Francisco del Castillo. 
El 26 de diciembre de 1642 murió el pintor Simón Fogos, Fuegos o Cienfuegos, que había nombrado como albaceas a su mujer María Muñoz y a Juan de Solís que vivía en la red de San Luis o más exactamente a su salida, en el inicio de la calle de Hortaleza ${ }^{18}$. Fogos fue uno de los más importantes tratantes de pintura de la época en Madrid y si su amistad con Solís llegó hasta el punto de nombrarle testamentario debemos pensar que tuvo que vender numerosas obras hechas por su amigo. Sería importante también la vecindad que habían mantenido, pues Fogos murió en una casa de la carrera de San Jerónimo frontera de la Victoria, donde vivía Solís en 1629.

El mismo año 1642 casó Juan de Arellano con María de Corcuera. Según Palomino, el pintor había enviudado seis años antes, o sea, en 1636. Su primer matrimonio sería poco anterior a esta fecha, coincidiendo, como era usual, con el abandono del obrador de su maestro Solís y el inicio de su actividad como pintor independiente; recuérdese, sin embargo, que sus primeras obras conocidas en la actualidad no están datadas hasta 1646. Pero lo que nos importa recordar aquí es que ya Palomino afirmó que la segunda esposa de Arellano, a quien da el título de «doña», era parienta de Juan de Solís. Ignoramos el grado de parentesco, pero posiblemente Mariana de Corcuera, la segunda esposa de Solís desde 1632, era hermana de la mujer de Arellano y no cabe duda de que la relación se estableció en el curso de la estancia de Arellano en el obrador de su maestro.

Hace ya bastantes años documentamos la actividad de Juan de Solís en la capilla de la Virgen del Amparo de la iglesia parroquial de Colmenar de Oreja (Madrid), que traemos ahora al recuerdo en este nuevo contexto ${ }^{19}$. Estante en dicha villa, firmó sendas escrituras con don Bernardino de Cárdenas, conde de Colmenar de Oreja, en 1647, obligándose el 23 de julio a "pintar y dorar por de dentro la dicha capilla de Nuestra Señora y la rreja della de oro y açul conforme las condiciones que tiene hechas el padre fray Lorencio de San Nicolás» y el 24 de agosto del mismo año a «dorar, pintar, estofar y colorir el rretablo de Nuestra Señora del Anparo questá en la dicha capilla en toda perfectión, conforme las condiciones echas entre su Señoría y el dicho Juan de Solís... todo a satisfación del padre fray Laurencio de San Nicolás». Por la primera labor recibiría 4.600 reales y por la segunda 5.500 reales; los plazos para la conclusión de las obras serían de cincuenta días y dos meses respectivamente. El retablo no se ha conservado y no quedan tampoco restos de pintura ni en los muros de la capilla ni en la reja. En cualquier caso, según se puede observar, se trataba de labores propias de un pintor dorador, como ya las habría realizado en el Buen Retiro.

Solís tuvo también relación con el pintor Antonio Puga, pues en su testamento de 9 de marzo de 1648 éste reconoce que le debía 16 reales. Recuérdese que Puga pintaba paisajes, quizá con carácter decorativo, y que cumplió encargos para nobles y otros personajes del entorno palatino; ambos hechos pudieron constituir las vías para relacionarse con Solís.

El pintor otorgó testamento el 12 de octubre de 1649 nombrando herederos a su esposa y a los hijos de su primer matrimonio, Francisco y María, ésta ya casada con el ensamblador Gabriel Martínez. Los testamentarios fueron el batidor de oro Diego Alario y Angelo Nardi, pintor del Rey; el 26 de septiembre de 1654 añadió un codicilo, estando enfermo y privado de la vista, para sustituir a los albaceas - pues uno había fallecido y el otro estaba impedido- por su antiguo oficial Arellano y el grabador Pedro de Villafranca, nombrado tallador del Rey al mes siguiente, a quien conoció quizás en el entorno de artífices palatinos. La amistad con Nardi pudo surgir por la vecindad pues también vivió en la red de San Luis y hemos de recordar que Francisco So-

18 Matías Fernández García, «Pintores de los siglos xvı y xvıI, que fueron feligreses de la parroquia de San Sebastián», A.I.E.M. XVII (1980), 116.

19 José Manuel Cruz Valdovinos, «Fray Lorenzo de San Nicolás y la capilla de Nuestra Señora del Amparo en Colmenar de Oreja (Madrid)", Goya 145 (1978), 29-30. La documentación que se cita procede del archivo parroquial de la Villa. 

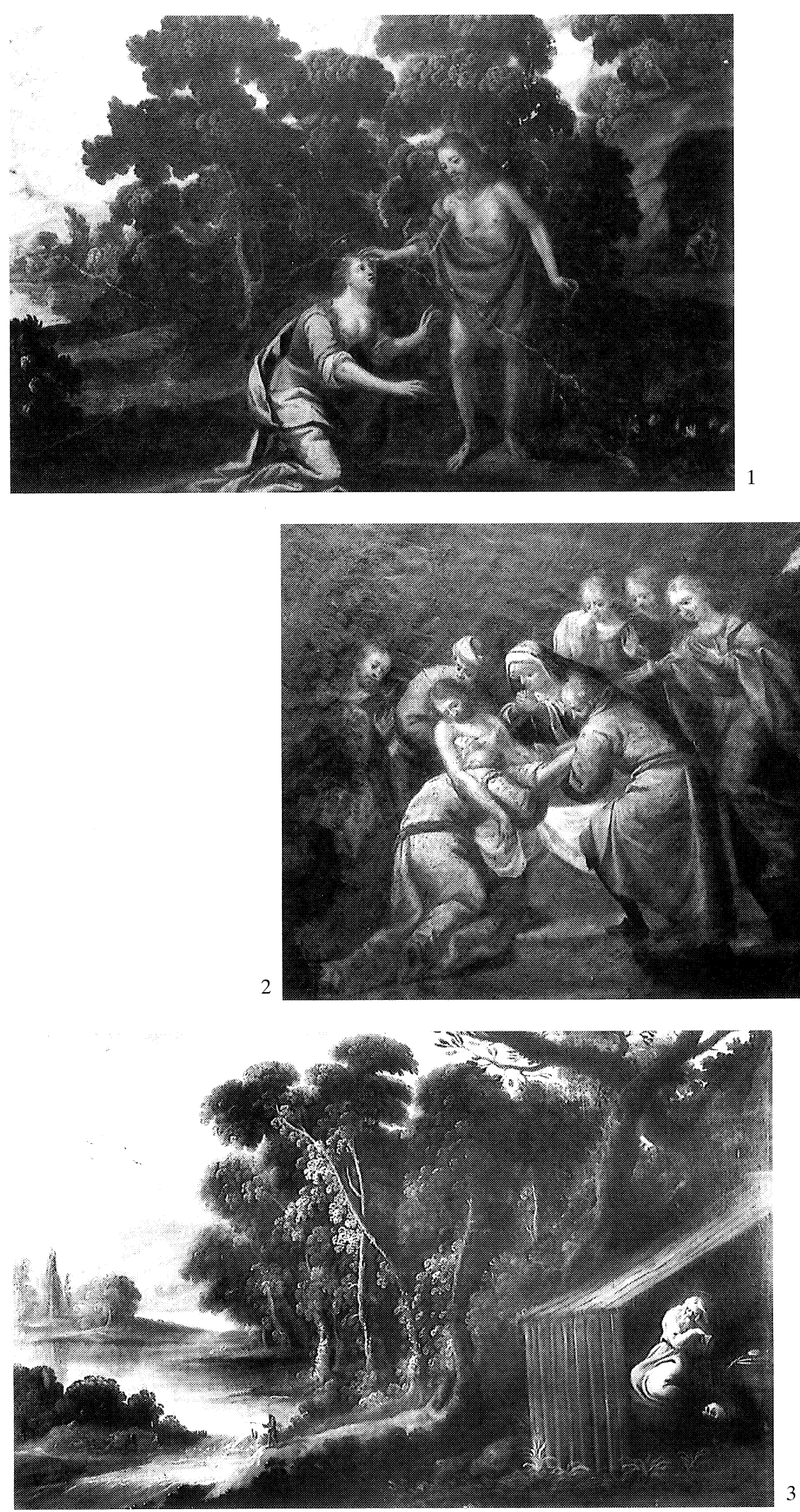

Fig. 1. Juan de Solís, Noli me tangere. Segovia, Museo de la Catedral.

Fig. 2. Juan de Solís, Entierro de Cristo. Segovia, Museo de la Catedral.

Fig. 3. Juan de Solís, Paisaje con ermitaño. Pamplona, Museo de Navarra. 

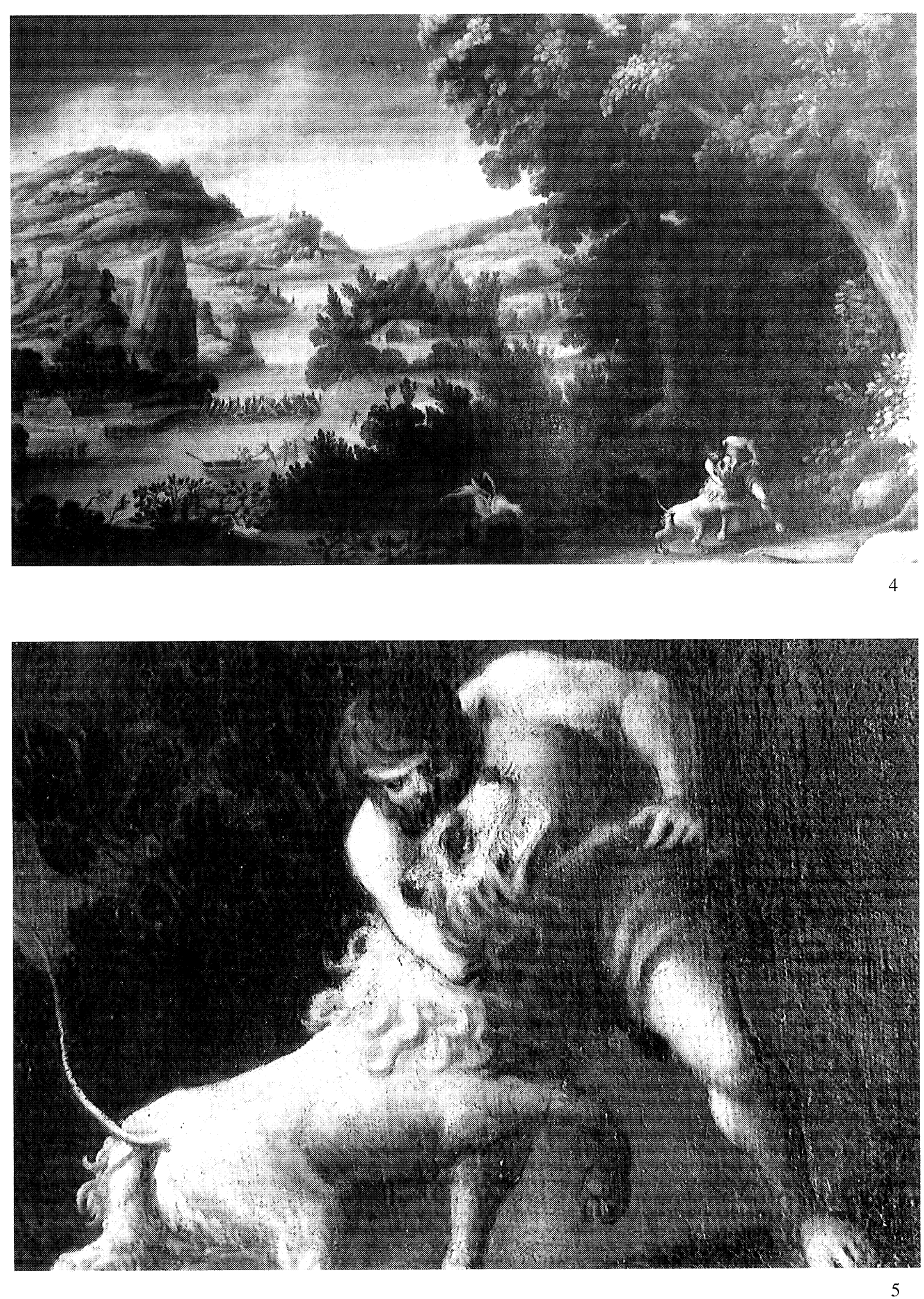

Fig. 4 y 5. Juan de Solís, conjunto y detalle de Paisaje con Hércules luchando con el león de Nemea. Colección particular. 

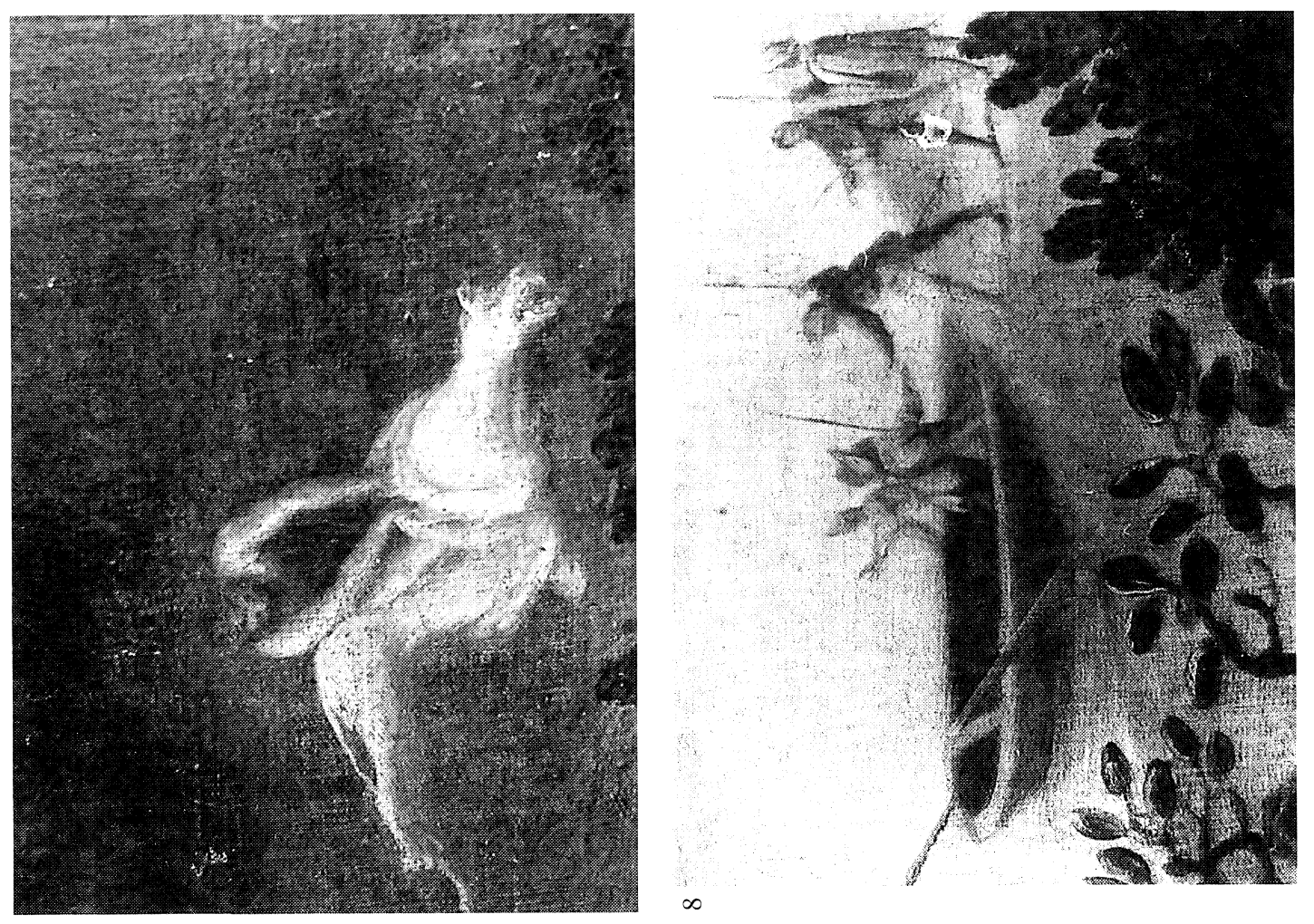

r

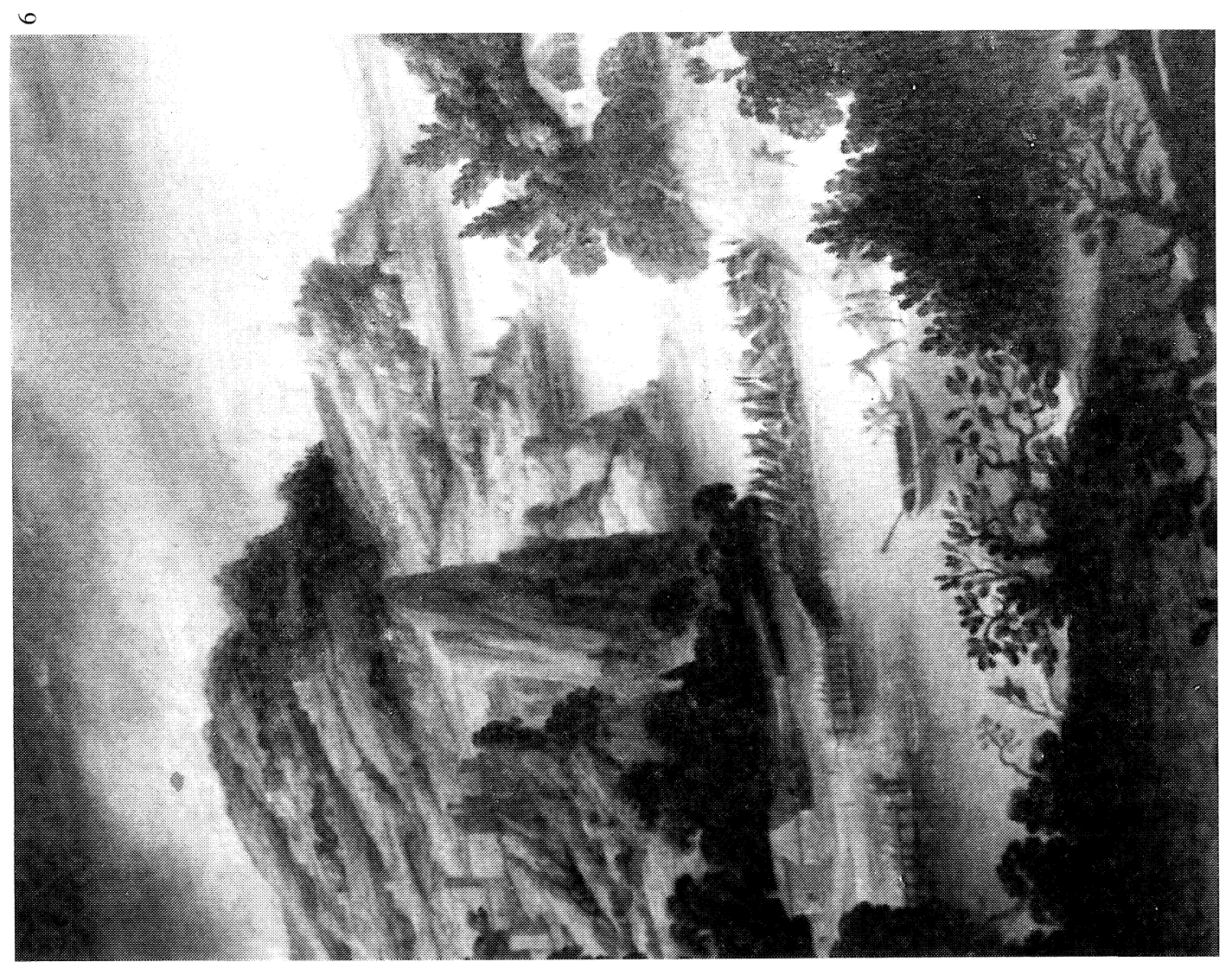

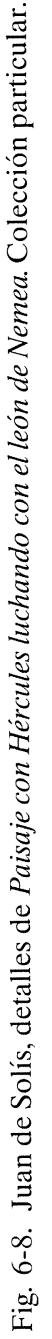


lís en 1659 solicitó la plaza de pintor del Rey para sustituir a Nardi en sus ausencias; aunque no se le concedió, haría su petición probablemente de acuerdo con el italiano.

Damos aquí a conocer la fecha de muerte de Juan de Solís, que tuvo lugar el 30 de septiembre de 1654 en su casa de la calle de Hortaleza, donde había vivido seguramente desde su segundo matrimonio ${ }^{20}$.

Por lo que respecta al catálogo del pintor, María Angeles Mezquíriz publicó en 1968 el Paisaje con ermitaño $(1,1 / 4 \times 2$ varas) que se conserva en el museo de Navarra con firma que recoge su nombre (Fig. 3). Con razón consideran Angulo y Pérez Sánchez que ha de ser obra avanzada. Pensamos que el uso del nombre completo y no del apellido sólo, como hizo en las demás pinturas conocidas, debe indicar que ya su hijo Francisco estaba en activo. Precisamente la obra más antigua conocida de éste - Anunciación de los Redentoristas de Madrid, datada en 1656, apenas dos años después de la muerte de su padre- lleva firma con el nombre. Y sólo se conoce en otra obra de Francisco una firma tan completa: es el retablo de San Marcos de la catedral vieja de Vitoria, razonablemente catalogado por Aurora Miró como pieza temprana. Más tarde, fallecido ya su padre y por tanto sin posibilidad de confusión, firmó tan sólo con el apellido, como había hecho Juan de Solís antes de que su hijo empezara a trabajar.

En 1983, Angulo y Pérez Sánchez dieron a conocer una serie de otros cuatro Paisajes conservados en colección privada de Madrid (1,1/2 × 2,1/4 varas) con los santos Antonio Abad, Jerónimo, Benito y Bernardo respectivamente; los dos últimos están firmados sólo con el apellido.

A estas obras queremos añadir otras. En primer lugar, restituyendo algunas que se mencionaron o publicaron como pintadas por su hijo Francisco. Al morir en 1666 Jerónima de Villarreal, cuya condición social no se menciona, tenía tres países de Solís $(1,1 / 2 \times 2$ varas) que Julián González tasó conjuntamente en 750 reales (tenían marco negro); la identificación se debió sin duda a la aparición de firma o firmas. Mercedes Agulló publicó el documento y en el índice de su libro figuran como obra de Francisco, quien no consta que pintara paisajes ${ }^{21}$.

Mucha mayor importancia tiene la serie de ocho pinturas sobre mármol con asuntos de la Pasión de Cristo $(1 / 2 \times 3 / 4$ de vara) que se guarda en el museo de la catedral de Segovia; Ecce Homo y Entierro de Cristo están firmadas tan sólo con el apellido (Fig. 9). Fueron dadas a conocer por Fernando Collar de Cáceres en 1991 como obra avanzada de Francisco Solís sin expresar duda alguna ni plantear siquiera la posibilidad de que sean obra de su padre Juan ${ }^{22}$ (Fig. 2). A nuestro entender, la serie debió ser pintada por Juan de Solís. El propio autor demuestra la influencia de estampas flamencas en la mayor parte de las piezas, lo que disimula el estilo propio del autor y la hechura sobre mármol no ayuda a la comparación con pinturas sobre lienzo. Pero las diferencias con las muchas obras conocidas de Francisco Solís son evidentes y Collar de Cáceres en todo su largo comentario tan sólo señala una similitud entre las figuras del Ecce Homo y las del retablo de San Marcos de la catedral vieja de Vitoria, obra temprana como ya se dijo. La fisonomía de los personajes, su canon poco esbelto, la composición de figura insistente en verticales y frontalidades o de simple sinuosidad si están arrodilladas, los efectos de claroscuro que confieren cierta dureza a los pliegues de los vestidos, las carencias de dinamismo en el tratamiento de los cielos y la eliminación de elementos secundarios y de ambientación ornamental son caracteres que corresponden a Juan, pero no a Francisco Solís. Ni siquiera es suficiente la relación que existe, por ejemplo, en la manera de plegar los vestidos de San Simón y San Judas o de tratar algunos elementos de rocas y plantas en el San Marcos (los tres del retablo

\footnotetext{
20 Agradecemos la noticia a nuestra amiga, la licenciada doña Soledad Cánovas del Castillo.

21 Mercedes Agulló y Cobo, Más noticias sobre pintores madrileños de los siglos XVI al XVIII, Madrid, 1981 (Ayuntamiento de Madrid), 96.

22 Fernando Collar de Cáceres, "Una serie de la Pasión de Cristo firmado por Francisco de Solís», Anuario del Departamento de Historia y Teoría del Arte (U.A.M.), III (1991), 93-100.
} 
de Vitoria) que, además, son obras tempranas y por ello todavía con detalles procedentes de la pintura paterna. En sentido positivo bastaría comparar el paisaje con arboleda recortada sobre el cielo claro y difuminado último término acuático de la escena Noli me tangere de Segovia (Fig. 1) con cualquiera de los que aparecen en las obras conocidas de Juan de Solís, incluída la que luego damos a conocer. La relación es mayor con el país del museo de Navarra y con el que presentamos, obras que con la serie segoviana han de ser tardías; convencionalmente las datamos en torno a 1650. La coincidencia es estricta en la manera de hacer surgir las copas de los árboles como pequeños borbollones, aclarando el color de las hojas, redondas y ovales, que aparecen en primer término de manera que brillan y resaltan sobre el boscaje de fondo más oscuro. También la forma de recortar a contraluz en primeros términos pequeñas matas y arbustos es la misma en los países firmados por Juan de Solís que en el Calvario segoviano.

En último lugar presentamos una obra inédita de colección particular vasca, al óleo sobre lienzo, que mide $127 \times 206 \mathrm{~cm}(1,1 / 2 \times 2,1 / 2$ varas), poco más que los de la serie madrileña; está firmada Solis, ft en el ángulo inferior derecho (Fig. 10) ${ }^{23}$. Se trata de un paisaje con una pequeña escena, o mejor, dos, que representan a Hércules luchando con el león de Nemea (Figs. 4-8). De acuerdo con el mito, el héroe, tras golpear al animal inútilmente con la clava -que está caída en primer plano junto al arco y la flecha también desechados-, agarró al león con las manos para estrangularle -que es la actitud en que le representa el pintor de forma destacada a la derecha- y luego, una vez muerto, le desolló -como se ve en el centro de la obra ligeramente en segundo término-. La pintura se completa en su mitad izquierda con un paisaje de peñascos, casas simples, un castillo al fondo y algunas barcas con figurillas que embarcan o desembarcan, carentes de protagonismo.

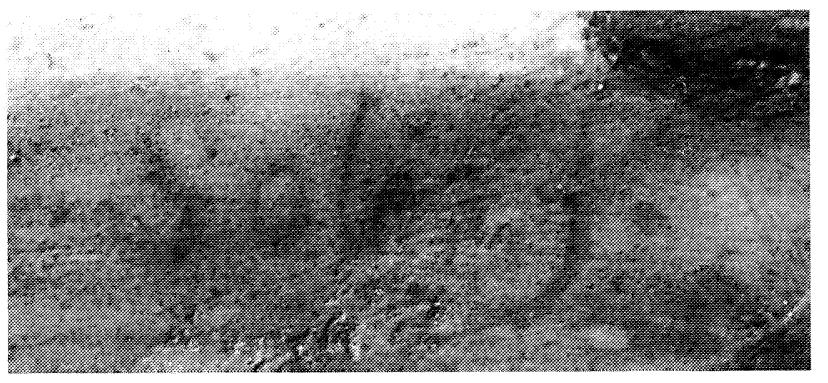

Fig. 9. Firma de Juan de Solís en el Entierro de Cristo. Segovia, Museo de la Catedral.

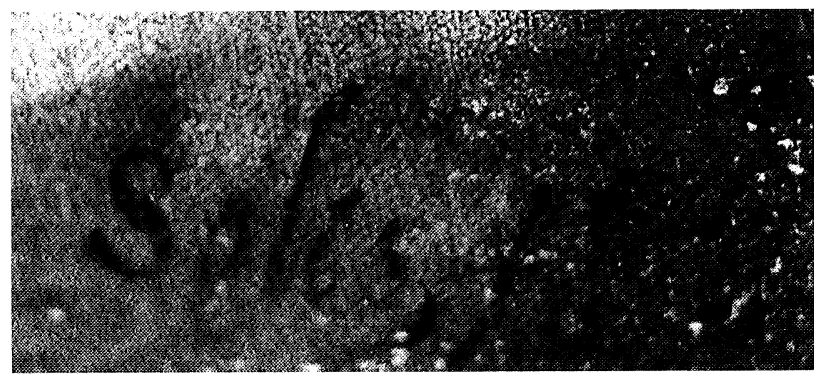

Fig. 10. Firma de Juan de Solís en el Paisaje de Hércules luchando con el león de Nemea. Colección particular.

23 Debemos el conocimiento de la pintura y sus fotografías a nuestro amigo el académico vasco don Rafael Munoa, a quien desde aquí agradecemos públicamente su amabilidad. Deseamos dar las gracias también a doña María Angeles Mezquíriz, directora del museo de Navarra, por la generosidad y prontitud con que nos envió la fotografía que publicamos y al licenciado don Javier Montalvo que hizo expresamente para nosotros las fotografías de las obras segovianas, dándonos una prueba más de su amistad. 
La composición de esta obra es similar a la de los demás paisajes conocidos de Juan de Solís, cerrando con un bosque una parte y abriendo entre peñas y hasta la lejanía una zona acuática. También la inclusión de figuras o escenas en un país es normal aunque la pieza que comentamos destaca de una parte porque las figuras son más pequeñas respecto al paisaje que en los ejemplares anteriormente conocidos y, por otra, porque aparecen dos escenas, simultáneamente representadas aunque sucesivas en el tiempo, del mito narrado. Es cierto que en algunas otras pinturas aparece alguna escena secundaria más o menos relacionable iconográficamente o no con el santo ermitaño principal. Pero no con la equivalencia plena ni con la secuencia temporal de las que aquí se muestran. Sistema representativo comparable en cierta medida a lo que había hecho Velázquez en su lienzo de las Historias de San Pablo ermitaño y San Antonio abad (museo del Prado) colocado probablemente en 1633 como cuadro de altar en la ermita de San Pablo del Buen Retiro.

Sin pretender comparaciones impertinentes por la diferencia de calidad y novedad, que afectan también a la técnica, al color, a las formas vegetales y rocosas, no debemos desaprovechar la ocasión de señalar que la obra de Velázquez -colocada además en una ermita del Buen Retiro, para donde trabajó Solís según se ha recordado- hubo de suscitar algún pensamiento e influencia en su coetáneo. Así cabe apreciarlo tanto en lo indicado sobre la conjunción de escenas como en el reparto de zonas llenas y vacías en el paisaje, en la apertura a lejanas profundidades o incluso en el detalle de los pequeños arbustos de primer término.

Indiquemos, por último, que el colorido de la obra de Solís, oscurecido y algo amarillento por el paso del tiempo, se mueve entre verdes y ocres con notables matices conjugados con luces y sombras que introducen una grata variedad. 